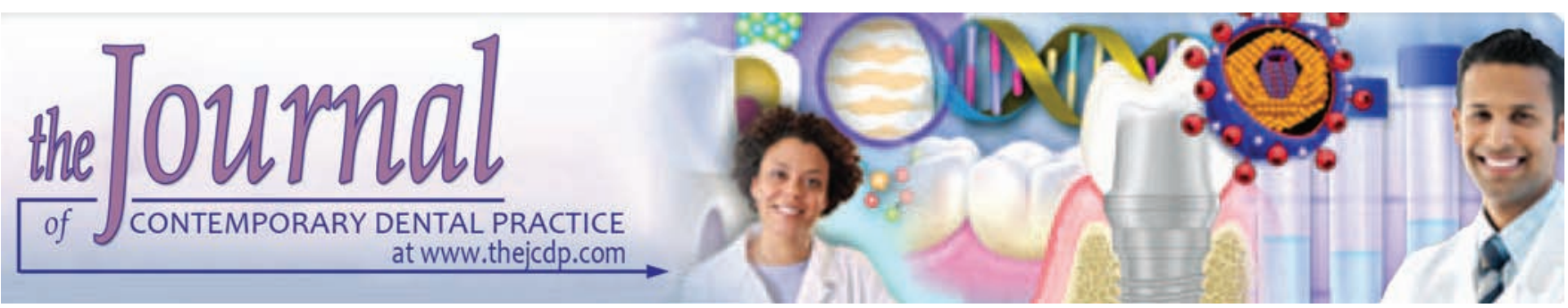

\title{
Protective Effect of Adhesive Systems associated with Neodymium-doped Yttrium Aluminum Garnet Laser on Enamel Erosive/Abrasive Wear
}

${ }^{1}$ Erica Crastechini, ${ }^{2}$ Alessandra B Borges, ${ }^{3}$ Klaus Becker, ${ }^{4}$ Thomas Attin, ${ }^{5}$ Carlos RG Torres

\begin{abstract}
Aim: This study evaluated the efficacy of self-etching adhesive systems associated or not associated with the neodymiumdoped yttrium aluminum garnet (Nd:YAG) laser on the protection against enamel erosive/abrasive wear.
\end{abstract}

Materials and methods: Bovine enamel specimens were demineralized with $0.3 \%$ citric acid ( 5 minutes). The samples were randomly assigned to eight groups $(n=20)$ : SB - Single Bond Universal (3M/ESPE); $\mathrm{SB}+\mathrm{L}-$ Single Bond Universal + laser $(80 \mathrm{~mJ} / 10 \mathrm{~Hz}) ; \mathrm{FB}$ - Futurabond U (Voco); FB+L Futurabond U + laser; GEN - G-aenial bond (GC); GEN+L G-aenial bond + laser; $\mathrm{L}$ - laser irradiation; and $\mathrm{C}$ - no treatment. The laser was applied before light curing. The samples were subjected to erosive/abrasive challenges $(0.3 \%$ citric acid -2 minutes and tooth brushing four times daily for 5 days). Enamel surface loss was recovered profilometrically by comparison of baseline and final profiles. The adhesive layer thickness, retention percentage of the protective layer, and microhardness of cured adhesive were measured. Data were analyzed using one-way analysis of variance and Tukey's test (5\%).

Results: There were significant differences for all parameters $(p=0.0001)$. Mean values \pm SD and results of the Tukey's test were: Surface wear: GEN - $4.88( \pm 1.09) a, L-5.04 \pm 0.99) a$, FB - $5.32( \pm 0.93) a b, G E N+L-5.46( \pm 1.27) a b c, S B+L-5.78$ $( \pm 1.12)$ abc, $\mathrm{FB}+\mathrm{L}-6.23( \pm 1.25) \mathrm{bc}, \mathrm{SB}-6.35( \pm 1.11) \mathrm{c}$, and $\mathrm{C}$ $-6.46( \pm 0.61)$ c; layer thickness: GEN $-15.2( \pm 8.63) c$, FB -5.06 ( \pm 1.96$) a$, GEN + L - $13.96( \pm 7.07) b c, S B+L-4.24$ ( \pm 2.68$) a$,

\footnotetext{
1,2,5 Department of Restorative Dentistry, Institute of Science and Technology, São Paulo State University - UNESP, São José dos Campos, Brazil

${ }^{3,4}$ Clinic for Preventive Dentistry, Periodontology and Cariology Center of Dental Medicine, University of Zurich, Zurich Switzerland

Corresponding Author: Carlos RG Torres, Department of Restorative Dentistry, Institute of Science and Technology, São Paulo State University - UNESP, São José dos Campos, Brazil Phone: +551239479376, e-mail: carlosrgt@fosjc.unesp.br
}

$\mathrm{FB}+\mathrm{L}-9.03( \pm 13.02) \mathrm{abc}$, and SB $-7.49( \pm 2.80)$ ab; retention: GEN - 68.89 ( \pm 20.62$) c, F B-54.53( \pm 24.80)$ abc, GEN + L -59.90 ( \pm 19.79$) a b c, S B+L-63.37$ ( \pm 19.30$) b c, F B+L-42.23( \pm 17.68)$ a, and SB - $47.78( \pm 18.29) \mathrm{ab}$; microhardness: GEN -9.27 $( \pm 1.75)$ c; FB - $6.99( \pm 0.89)$ b; GEN + L - $6.22( \pm 0.87) a b ; S B+$ $\mathrm{L}-15.48( \pm 2.51) \mathrm{d}$; FB $+\mathrm{L}-10.67( \pm 1.58) \mathrm{c}$; SB -5.00 ( \pm 1.60$)$ a.

Conclusion: The application of Futurabond $U$ and G-aenial bond on enamel surface, as well as the Nd:YAG laser irradiation alone, was able to reduce the enamel wear. The use of laser after the adhesive systems did not improve their efficacy.

Clinical significance: Erosive/abrasive wear is a prevalent condition in clinical practice affecting many patients. The association of adhesive systems and Nd:YAG laser is of considerable clinical interest because it assesses new treatments to reduce the erosive/abrasive wear that would help dentists in clinical treatment decisions to reduce enamel wear and achieve a successful treatment.

Keywords: Adhesive systems, Dental abrasion, Dental erosion, Laser, Toothbrushing, Tooth wear.

How to cite this article: Crastechini E, Borges $A B$, Becker $K$, Attin T, Torres CRG. Protective Effect of Adhesive Systems associated with Neodymium-doped Yttrium Aluminum Garnet Laser on Enamel Erosive/Abrasive Wear. J Contemp Dent Pract 2017;18(10):859-866.

\section{Source of support: Nil}

Conflict of interest: None

\section{INTRODUCTION}

Dental erosion is characterized by a chronic localized loss of dental hard tissues, which involves their chemical removal by acids or chelation without bacterial involvement. Acids may have an extrinsic origin, such as soft drinks and fruit juices, or intrinsic, such as eating disorders and gastric reflux. ${ }^{1}$ Acid attack leads to the loss and softening of the enamel surface and reduces its wear resistance, making it more susceptible to the effects of mechanical abrasion, such as brushing and lip, cheek, 
and tongue rubbing. ${ }^{1,2}$ The erosion, abrasion, and attrition processes rarely occur alone, and the alternation between erosion and abrasion is considered the most frequent interaction. ${ }^{3}$

It is very difficult to control the possible multifactorial etiology of noncarious lesions. Therefore, strategies have been developed to prevent or stop the dental erosion and abrasion, with the use of different forms of fluoride agents, ${ }^{4}$ calcium-containing products, ${ }^{5}$ and surface agents, such as proteins and polymers. ${ }^{6,7}$ However, the data are conflicting regarding effective protection against erosion and abrasion.

The application of high-power lasers, such as Nd:YAG, $\mathrm{CO}_{2}$, erbium-doped yttrium aluminum garnet, ${ }^{8-10}$ in an attempt to increase the enamel resistance against demineralization, has also been investigated. ${ }^{11}$ Studies reported Nd:YAG laser as the most effective ${ }^{8,12}$ because the laser light is absorbed by hydroxyapatite and converted into heat that causes melting and fusing of the enamel structure and subsequent resolidification, decreasing its permeability. This modified surface shows a reduction of interprismatic areas, and consequently, less acid diffusion, increasing the demineralization resistance. ${ }^{13}$ Furthermore, laser irradiation promotes the formation of pyrophosphate, which can reduce the dissolution of hydroxyapatite, replacing the more soluble apatite carbonate for hydroxyapatite or fluorapatite in the presence of fluoride. ${ }^{11,14}$

The use of adhesive systems to form a resinous barrier on tooth surface preventing the contact of aggressive agents with dental substrate has also been investigated in laboratory and in situ studies, which tested the protection against dentin wear after it was subjected to erosion and abrasion, showing favorable results. ${ }^{15-17}$ Another study has applied the adhesive over the enamel, and its results showed decreased dissolution of enamel after acid challenge. ${ }^{18}$

The treatment of cavity walls with Nd:YAG laser has been investigated to improve the bond strength. However, it was shown that it reduces the bond strength to enamel and dentin. ${ }^{19,20}$ On the contrary, some authors tested the use of Nd:YAG laser immediately after the adhesive system application, before light curing, and found an improvement of bond strength, since the laser promotes recrystallization of hydroxyapatite along with the monomers, creating a new substrate with better adhesive properties to the composite. ${ }^{20,21}$ Taking into account that the use of the laser shows potential to act as a protective factor against enamel demineralization and that the adhesive by itself forms a protective layer over the tooth surface, it was assumed that the combined use of these two techniques could be even more effective in protecting the enamel against erosive/abrasives challenges.
The aim of this study was to evaluate the effectiveness of applying different self-etching adhesive systems, alone or associated with Nd:YAG laser in preventing erosive and abrasive wear of the tooth enamel. The null hypothesis tested was that no treatment tested was effective on reduction of enamel wear.

\section{MATERIALS AND METHODS}

\section{Preparation of the Specimens}

Freshly extracted bovine incisors were used, obtained from a 3-year-old cattle. The teeth were cleaned and then stored in a $0.1 \%$ thymol solution, during the period of samples preparation. ${ }^{22}$

A total of 160 cylindrical enamel-dentin samples were obtained from the buccal surface, using a diamond trephine mill with $3 \mathrm{~mm}$ of internal diameter. All specimens were embedded in acrylic resin using a cylindrical silicon mold with $6 \mathrm{~mm}$ diameter and $3.1 \mathrm{~mm}$ depth. At the bottom of the mold, there was a cavity at a second level with $3 \mathrm{~mm}$ diameter and $0.1 \mathrm{~mm}$ depth. Laterally to the mold, there was a projection in curved-lined shape producing a lateral groove in the specimen to aid the correct positioning of the sample in the profilometer. The samples were positioned within this internal cavity with the enamel surface toward the bottom of the mold. The mold was then filled with acrylic resin (Jet, Clássico Artigos Odontológicos Ltda, Campo Limpo Paulista, São Paulo, Brazil), immersed in water inside a pressurized pot (City Máquinas, Guarulhos, SP, Brazil), and subjected to a pressure of $30 \mathrm{psi}(0.2068 \mathrm{MPa})$ until complete curing, thus avoiding bubbles inside the acrylic resin.

The enamel surfaces were polished with P1200, P2400, and P4000 silicon carbide sandpapers (Extec Corp., Enfield, Connecticut, USA) under water cooling for 30 seconds, 60 seconds, and 2 minutes respectively. The specimens were cleaned in an ultrasonic bath with distilled water (Odontobrás, Ribeirão Preto, SP, Brazil) for 10 minutes to remove any debris.

To have parallel marks that could be used as guides for profilometric readings, two scratches were prepared on the polished surface of the acrylic resin, beside the enamel surface, using a custom-made device with a sharp steel tip. The specimens were then subjected to initial erosion with $0.3 \%$ citric acid solution $(\mathrm{pH}=2.6)$ for 5 minutes, to produce a softened layer over the enamel surface, normally found on eroded teeth which need treatment. ${ }^{23}$ For that, the samples were identified, placed in silicone holders, and immersed inside the acid solution, over a Kline multifunctional shaker at an average speed of $120 \mathrm{rpm}$, avoiding the saturation of calcium acid in contact with the sample, which would reduce their activity. The proportion used was $10 \mathrm{~mL}$ of citric 
acid per specimen, in a total volume of $1600 \mathrm{~mL} .{ }^{9}$ After that, the samples were removed from acid and washed in type I ultrapure water.

Baseline profiles of the enamel surfaces were measured. To ensure exact repositioning of the samples during the surface analyses, before and after experimental procedure, the profilometer (Maxsurf XCR, Mahr, Göttingen, Germany) was equipped with a custom-made jig. The diamond stylus of the profilometer moved $4.2 \mathrm{~mm}$ from the first scratch on the acrylic resin toward the enamel and then over to the second scratch. Three profile measurements were performed for each specimen at intervals of $0.25 \mathrm{~mm}$, the second one being exactly on the center of the enamel surface.

The samples were randomly assigned into eight groups ( $n=20)$, according to the type of adhesive system/ laser association: group SB - Single Bond Universal; group $\mathrm{SB}+\mathrm{L}-$ Single Bond Universal + Nd:YAG laser irradiation + light curing; group FB - Futurabond U; group FB $+\mathrm{L}-$ Futurabond U + Nd:YAG laser + light curing; group GEN - G-aenial bond; group GEN + L - G-aenial bond + Nd:YAG laser + light curing; group L - Irradiation of Nd:YAG laser; and group C - no treatment (control). In Table 1, the specifications of each adhesive system tested are presented.

\section{Surface Treatment}

Before treatment of the enamel surfaces, the acrylic resin was protected using a black plastic adhesive film (Contact, Vulcan, Irajá, RJ, Brazil) with a central hole of diameter $3 \mathrm{~mm}$. Thus, only the enamel was exposed to the treatments, protecting the parallel scratches previously prepared.

For groups SB, FB, and GEN, the adhesives were applied according to the manufacturer's instructions, using an applicator brush in constant agitation for 20 seconds for adhesives SB and FB and 10 seconds without agitation for GEN. After that, a blow of air was applied for 5 seconds, and a light curing was performed for 10 seconds with a light-emitting diode device (Elipar Free Light 2, 3M/ESPE, St. Paul, MN, USA), with a power density of $700 \mathrm{~mW} / \mathrm{cm}^{2}$.
For groups with adhesive/laser association, after the application of adhesive systems according to the manufacturer's instructions and the blow of air has been applied, the sample's surface was irradiated with Nd:YAG laser (Pulse Master 600IQ, American Dental Technologies, Corpus Christi, Texas, USA), emitting a wavelength of 1,064 $\mathrm{nm}$ and using an optical fiber of $320 \mu \mathrm{m}$. A frequency of $10 \mathrm{~Hz}$ and energy of $80 \mathrm{~mJ} /$ pulse, with a power of $0.8 \mathrm{~W}$, were set on the device. Light was applied without contact, with the fiber end at a distance of $3 \mathrm{~mm}$ from the sample. The enamel surface was scanned in all directions (vertical, horizontal, and transversal) for 60 seconds with the optical fiber positioned perpendicular to the surface to promote a homogeneous irradiation. Those parameters were based on previous studies and considered safe, not causing injuries to the pulp. ${ }^{8,24,25}$ After that, light curing of the adhesive was performed for 10 seconds. In Group L, only the irradiation of Nd:YAG laser over enamel surface was performed, using the same parameters described earlier, while Group $C$ received no treatment (control).

The microhardness (Knoop hardness number, KHN) of the adhesive layer was measured for all groups that received adhesive, using a microhardness tester (FM-700, Future-Tech, Tokyo, Japan) with a Knoop indenter, using a load of 10 gm for 10 seconds. ${ }^{26}$ Three indentations were performed on each specimen with $100 \mu \mathrm{m}$ of distance between them, and the mean value was calculated.

The samples were again subjected to the profilometric reading to evaluate the adhesive layer thickness and certify that no adhesive was present over the prepared scratches, which would affect the proper repositioning of the measured profiles. The baseline profiles obtained after the initial reading were superimposed to these profiles, to calculate the thickness of each adhesive layer deposited on the enamel surface.

\section{Erosive and Abrasive Challenges}

The erosive/abrasive challenges consisted of immersion of the specimens inside the acid solution for 2 minutes, followed by immersion in artificial saliva for 1 hour, and then 40 cycles of brushing and immersion

Table 1: Composition and specifications of the adhesive systems applied

\begin{tabular}{|c|c|c|c|}
\hline Adhesive system & Composition & Manufacturer & Batch number \\
\hline Single bond ${ }^{\circledR}$ universal & $\begin{array}{l}\text { Nanoparticles of silica, Bis-GMA, HEMA, dimethacrylates, ethanol, } \\
\text { water, photoinitiator, and a functional copolymer of polyacrylic and } \\
\text { polyalkenoic acids }\end{array}$ & $\begin{array}{l}\text { 3M/ESPE, St. Paul, } \\
\text { MN, USA }\end{array}$ & 504834 \\
\hline Futurabond $\mathrm{U}^{\circledR}$ & $\begin{array}{l}\text { 2-Hydroxyethyl methacrylate, Bis-GMA, HEDMA, methacryloyloxy } \\
\text { propyl dihydrogen phosphate, urethane dimethacrylate }\end{array}$ & $\begin{array}{l}\text { Voco, Cuxhaven, } \\
\text { Germany }\end{array}$ & 130847 \\
\hline G-aenial ${ }^{\mathrm{TM}}$ Bond & $\begin{array}{l}\text { Acetone, distilled water, dimethacrylate, } \\
\text { methacryloxyethyltrimellitate anhydride, phosphoric acid ester } \\
\text { monomer, silicon dioxide and photoinitiator }\end{array}$ & $\begin{array}{l}\text { GC Incorporation, } \\
\text { Itabashi-ku, Tokyo, } \\
\text { Japan }\end{array}$ & 1205101 \\
\hline
\end{tabular}

Bis-GMA: Bisphenol A-glycidyl methacrylate; HEMA: 2-hydroxyethyl methacrylate; HEDMA: 1,6-hexanediol dimethacrylate 
in artificial saliva for 1 hour, four times daily for 5 days. ${ }^{27}$ During the night, the specimens were stored in artificial saliva.

For $\mathrm{pH}$ cycling, a $0.3 \% \mathrm{w} / \mathrm{v}$ citric acid solution $(\mathrm{pH}$ 2.6) was prepared. The samples were placed in holders and immersed inside the acid solution, over a Kline multifunctional shaker at an average speed of $120 \mathrm{rpm}$. The proportion used was $10 \mathrm{~mL}$ per specimen of citric acid in a total volume of $1600 \mathrm{~mL} .{ }^{9}$ After each demineralization, the samples were simultaneously removed from the acid and then transferred to another plastic container containing $1600 \mathrm{~mL}$ of new artificial saliva under stirring for 1 hour, avoiding the precipitation of artificial saliva during the process. The artificial saliva formulation applied was proposed by Gohring et $\mathrm{al}^{28}$ at $\mathrm{pH}$ 7.0.

For the abrasive cycle, the specimens were placed on a holder, with a metal perforated mask protecting the acrylic resin and the scratches of the wear, exposing only the enamel area. They were then taken to a tooth brushing machine (MEV - 2T, Odeme, Luzerna, SC, Brazil) and brushed for 40 strokes, using a flat toothbrush (Ultra Professional, Sanifil, Curitiba, PR, Brazil) and a load of $200 \mathrm{gm}$, immersed in a toothpaste slurry, and prepared with a regular toothpaste (Colgate maximum anticaries protection, Colgate-Palmolive, São Bernardo do Campo, SP, Brazil) diluted in artificial saliva $(1: 3 \mathrm{w} / \mathrm{w})$. To have a homogeneous brushing, the long axis of the brush was positioned at an angle of $12^{\circ}$ to the direction of the movement. ${ }^{29}$

Three profiles of enamel surfaces after abrasive and erosive challenge were measured and the comparisons were carried out with Contour analyses software (Mar Surf XCR 20 4.50-07 SP3, Mahr GmbH, Göttingen, Germany). The initial and final profiles were exactly superimposed using the parallel scratches, as reference, and the distance between them was determined (in micrometers). The mean of the three readings for each sample was obtained and used for data analysis.

\section{Measurement of Adhesive Retention}

The percentage of adhesive layer retention after erosive/ abrasive wear was calculated. For that, the exposed enamel surface was stained with $7 \%$ aqueous hematoxylin solution for 5 minutes. After that, the surface was washed with water and dried with a blow of air. Pictures of each sample were obtained with a stereomicroscope (Carl Zeiss - Stemi 2000-C; Göttingen, Germany) using a magnification of $40 \times$. The area of exposed enamel was measured using image analysis software (UTHSCSA Image tools for Windows, version 3.00, San Antonio, Texas, USA). The percentage of exposed enamel was calculated in relation to the total enamel area.

\section{Statistical Analysis}

Data were analyzed for normality using the KolmogorovSmirnov test. One-way analysis of variance (ANOVA) and Tukey's test were applied to compare the groups. The data for wear, retention, and adhesive layer thickness were analyzed separately. The significance level was 5\%.

\section{RESULTS}

The results showed significant difference among the groups for wear, adhesive layer thickness, retention, and microhardness (Table 2). The groups GEN, L, and FB exhibited significantly less wear than the control group (Graph 1). The group GEN showed highest mean of adhesive layer thickness but statistically similar to groups GEN + L and FB + L. The group GEN also exhibited highest mean of adhesive retention but statistically similar to groups FB, Gen $+\mathrm{L}$, and FB + L. The group SB + L showed a significantly higher microhardness in relation to the other groups. The application of Nd:YAG laser over the adhesive increased the microhardness for Single Bond and Futurabond and diminished for G-aenial bond.

For illustrative purposes, adhesive retention images of a representative sample for each group are presented in Figure 1.

Table 2: Means of wear, layer thickness, retention, and microhardness (KHN) and results of ANOVA and Tukey's test

\begin{tabular}{|c|c|c|c|c|}
\hline Groups* & Wear mean $\pm S D$ & Thickness mean $\pm S D$ & Retention mean $\pm S D$ & $K H N$ mean $\pm S D$ \\
\hline G-aenial & $4.88 \pm 1.09 a$ & $15.27 \pm 8.63 c$ & $68.89 \pm 20.62 c$ & $9.27 \pm 1.75 c$ \\
\hline Laser & $5.04 \pm 0.99 a$ & - & - & - \\
\hline Futurabond U & $5.32 \pm 0.93 a b$ & $5.06 \pm 1.96 a$ & $54.53 \pm 24.80 a b c$ & $6.99 \pm 0.89 b$ \\
\hline G-aenial+laser & $5.46 \pm 1.27 a b c$ & $13.96 \pm 7.07 b c$ & $59.90 \pm 19.79 a b c$ & $6.22 \pm 0.87 a b$ \\
\hline Single Bond U+laser & $5.78 \pm 1.12 a b c$ & $4.24 \pm 2.68 a$ & $63.37 \pm 19.30 \mathrm{bc}$ & $15.48 \pm 2.51 d$ \\
\hline Futurabond U+laser & $6.23 \pm 1.25 b c$ & $9.03 \pm 13.02 a b c$ & $42.23 \pm 17.68 a$ & $10.67 \pm 1.58 c$ \\
\hline Single Bond U & $6.36 \pm 1.11 \mathrm{c}$ & $7.49 \pm 2.80 a b$ & $47.78 \pm 18.29 a b$ & $5.00 \pm 1.60 a$ \\
\hline Control & $6.46 \pm 0.61 c$ & - & - & - \\
\hline \multirow[t]{2}{*}{ ANOVA results } & $p=0.0001$ & $p=0.0001$ & $p=0.0001$ & $p=0.0001$ \\
\hline & $f=6.575$ & $f=8.002$ & $f=4.796$ & $f=109.125$ \\
\hline
\end{tabular}

*For each parameter, the ANOVA results and the comparisons with Tukey's test are presented separately on columns. The sets followed by the same letters do not show significant differences; SD: Standard deviation 


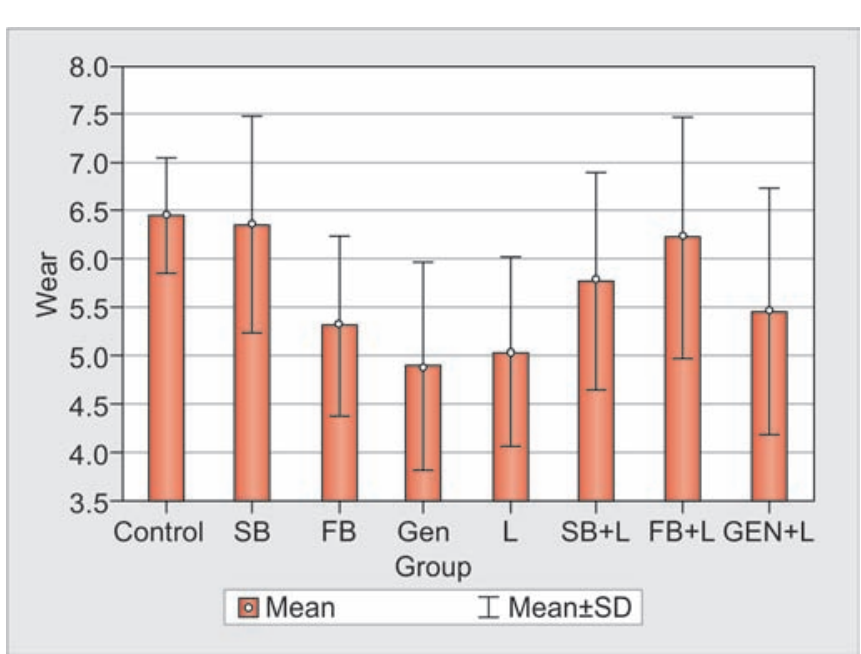

Graph 1: Graph of means and standard deviation obtained after wear for the groups tested

\section{DISCUSSION}

In this study, the results showed that despite the different treatments, all groups suffered some degree of wear. However, some of them showed significantly lower values than the control group (Table 2, Graph 1).

In relation to the treatment with Nd:YAG laser alone, the results obtained in our study showed that it is effective in terms of decreasing the wear caused by the erosive and abrasive cycle (Table 2, Graph 1). Its effectiveness can be related to its ability to decrease the enamel permeability, reducing the diffusion of acids during the erosive challenges, minimizing thereby the demineralization..$^{13}$ In addition, the laser irradiation raises the surface temperature to $650^{\circ} \mathrm{C}$, favoring the formation of pyrophosphate, which can reduce the dissolution of hydroxyapatite, replacing the apatite carbonate which is more soluble for hydroxyapatite or fluorapatite in the presence of fluoride. ${ }^{11}$ On the contrary, the results in the literature regarding its effectiveness are conflicting. Some studies evaluated the application of Nd:YAG laser alone and combined with different forms of fluoride for protection against erosion and/or abrasion and concluded that laser alone is effective, but its association with fluoride resulted in the lowest wear. ${ }^{8,24}$ Other studies found that the Nd:YAG laser was not effective against enamel erosion and had no influence on the efficacy of fluoride. ${ }^{30,31}$ It has to be noted that the parameters of Nd:YAG laser are very important to its effects, and those applied in those studies are partially different from some of the parameters used in our method, such as fiber diameter, ranging from 250 to $320 \mu \mathrm{m}$; potency,
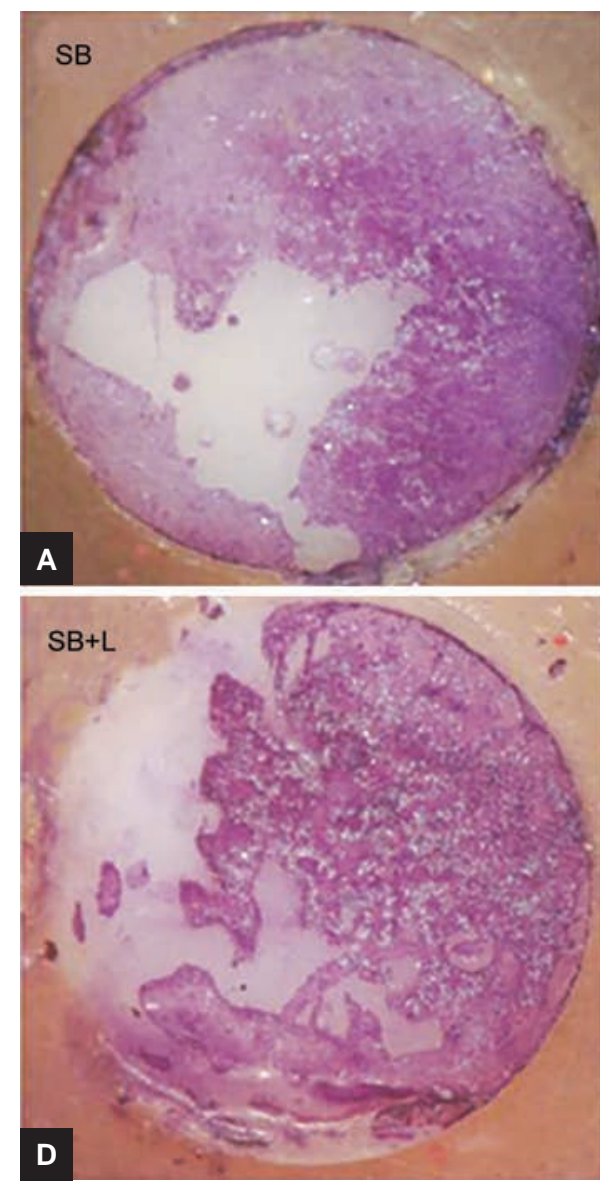
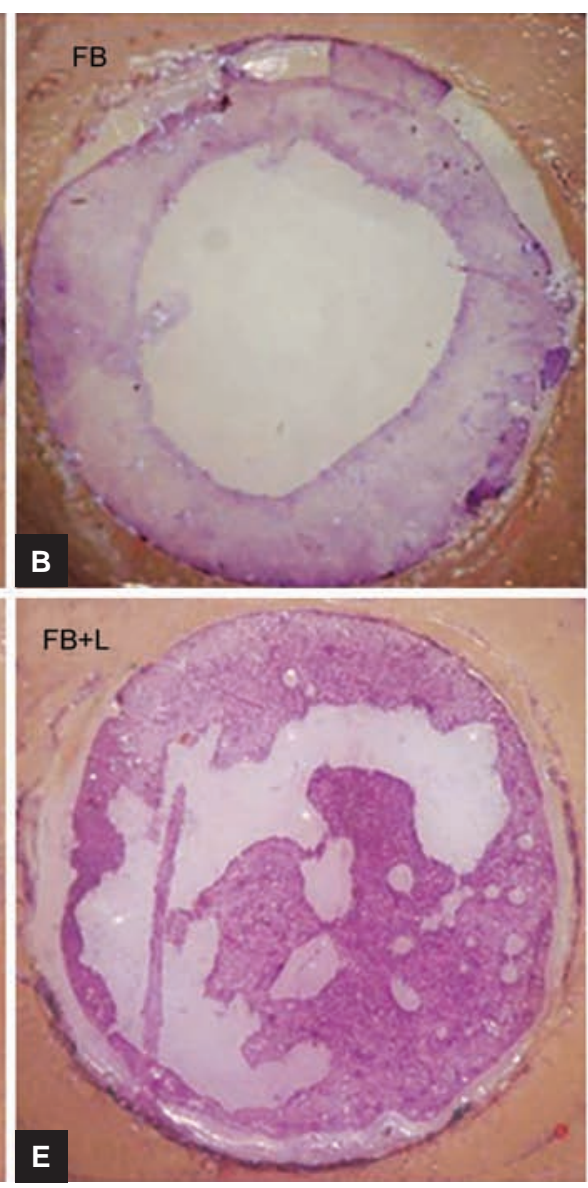
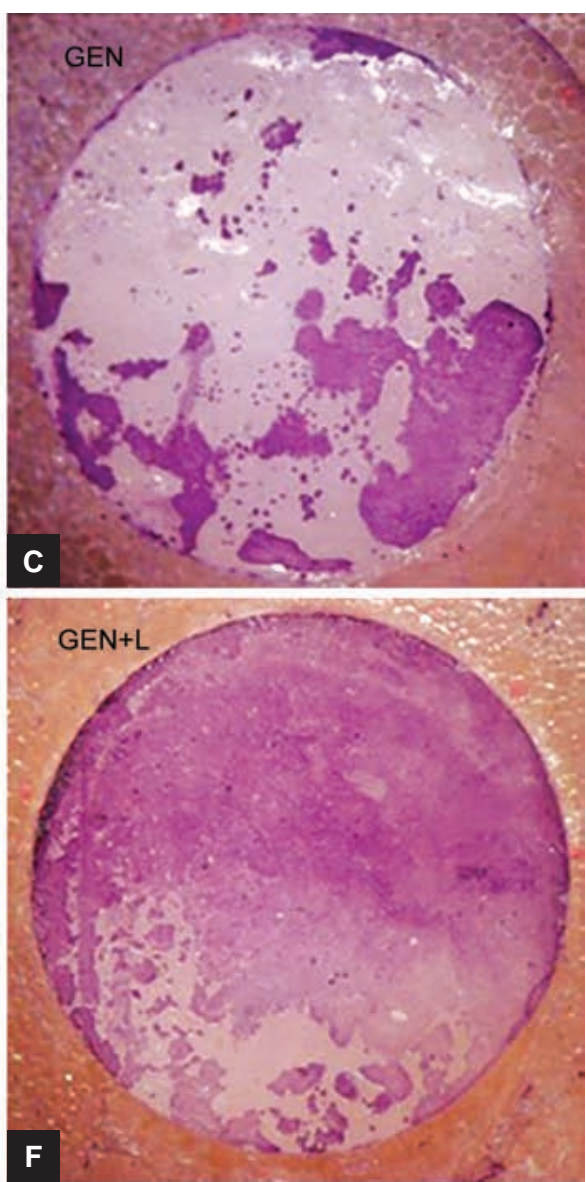

Figs $1 \mathrm{~A}$ to $\mathrm{F}$ : Examples of images showing the adhesive retention over the enamel surfaces after the treatments and erosive and abrasive cycle. The enamel can be seen in purple color and the adhesive layer can be seen in white color. SB: Single Bond Universal; FB: Futurabond U; GEN: G-aenial; SB+L: Single Bond Universal+laser; FB+L: Futurabond U + laser; GEN+L: G-aenial+laser (40×) 
ranging from 0.5 to $1 \mathrm{~W}$; and energy, which varies from 50 to $100 \mathrm{~mJ}$.

The energy parameters used in our study, which were $80 \mathrm{~mJ}$ and $10 \mathrm{~Hz}$, are considered safe, not causing injuries to the pulp or necrosis. White et $\mathrm{al}^{25}$ conducted a study in which various power parameters were tested to evaluate the temperature in the pulp chamber when applied at the pulpal cavity preparation wall in dentin. Those evaluations were conducted with a distance of 0.2 to 2 $\mathrm{mm}$ from the pulp, and the temperature was measured by thermocouples. It was concluded that for an energy of $100 \mathrm{~mJ}$ at a frequency of $10 \mathrm{~Hz}$, the pulp temperature reaches $4^{\circ} \mathrm{C}$ at a distance of $2 \mathrm{~mm}$ from the pulp, the parameters being within the limits established by Zach and Cohen, ${ }^{32}$ who reported that temperatures above $5.5^{\circ} \mathrm{C}$ cause injuries to the pulp. In the present study, $\mathrm{Nd}$ :YAG laser was applied over the enamel and not over dentin, so the final pulp temperature was assumed to be lower and even more secure. Based on our results, the use of Nd:YAG laser seems to be a promising alternative for the prevention of the progression of the erosion and abrasion. Nevertheless, it should be mentioned that these high-intensity laser devices are very expensive and can also be difficult to apply in the oral cavity depending on the region where the erosion/abrasion lesion is found.

The use of adhesive systems on enamel surface to prevent erosion and abrasion has also been tested, but there are few studies in the literature. The application of conventional and self-etching adhesive systems for protection against dentin wear was previously tested, and decreased erosive and abrasive wear was found. ${ }^{17}$ The use of adhesives to reduce enamel dissolution after carious acid challenge has also been tested. ${ }^{18}$ The adhesives tested in our study were chosen because they are self-etching and do not require prior application of a strong acid for getting retention, which would result in an additional wear on the already eroded surface, thus being more aggressive. Hermsen and Vrijhoef ${ }^{33}$ showed that application of $37 \%$ phosphoric acid for 15 seconds on the enamel surface promotes removal of about $4.9 \mu \mathrm{m}$.

The results obtained in the present study for the different adhesive systems showed a great variation. Although all the samples have shown wear after the erosive and abrasive cycles, Futurabond U and G-aenial bond adhesives showed smaller enamel lost than Single Bond Universal (Table 2). Those results can be related to the retention of the adhesive layer to the surface or to the resistance of this layer to toothbrushing abrasion.

Regarding the percentage of retention, G-aenial bond showed highest average than Futurabond and Single Bond (Table 2). This difference may be associated to the demineralization capacity of the acidic monomers present on each adhesive, directly related to the $\mathrm{pH}$ of the product. ${ }^{34}$ It is assumed that an adhesive that interacts more with the enamel may promote a better etching pattern and a better retention of the material to the surface. The $\mathrm{pH}$ values of the adhesives tested showed a relation with the protective effect presented by the adhesives. G-aenial bond had a more pronounced protective effect and has the lowest $\mathrm{pH}$ (1.5) of all the products tested, ${ }^{35}$ while the Futurabond $\mathrm{U}$, with a $\mathrm{pH}=$ 2.3 , presented an intermediate result and the Single Bond Universal, less effective, has $\mathrm{pH}=3.0 .^{36}$

The layer thickness formed by those materials also has a consistent relation with the protective effect. The G-aenial bond adhesive resulted in a layer with a thickness mean of $15.27 \mu \mathrm{m}$, while the Futurabond $U$ had $5.06 \mu \mathrm{m}$ and Single Bond Universal $7.49 \mu \mathrm{m}$. According to Azzopardi et al $^{16}$ the protective effect of the adhesive layer in the erosion prevention can be related to the thickness of the layer on the enamel surface or to the presence of the filler particles in the formulation, which would improve the physical properties of the polymer and would enhance the wear resistance. According to the manufacturers, G-aenial bond and Single Bond Universal adhesives have silica particles as filler, but this does not seem to have expressive effects in relation to the lower performance of Single Bond Universal. The measurement of microhardness of adhesive layer was consistent with our results (Table 2), since the Knoop microhardness for G-aenial bond was the highest one and the Single Bond Universal was the lower one. Examples of samples with different degrees of retention can be seen in Graph 1 .

Although the application of adhesive systems seems to be promising for reducing tooth wear caused by erosion and abrasion, its effect is not long-lasting. According to Azzopardi et al, ${ }^{17}$ the protection of the adhesives is limited to a period of 3 months, and the self-etching ones deteriorate faster than the total etch. The efficacy of the products was also related to the abrasion resistance among the products tested by them. Another aspect that can have an influence of the protective effect is the number of adhesive application, changing its layer thickness. According to Tajima et al, ${ }^{37}$ for some adhesive systems, just one layer may protect the surface, while in others, only one layer was not sufficient. However, for those materials, the application of two layers can be more effective. Therefore, after the application of adhesive systems, the professional should mind the preservation of the case and reapplication of the adhesive periodically. In our study, the application of additional layers could also improve the protective effect, although, in some areas, such as the occlusal surface, thicker layers could interfere with the occlusion.

The idea of association of laser with adhesive system for protection against erosion and abrasion on enamel emerged from the good results of studies using this technique to increase the bond strength of composite 
restorations. ${ }^{20,21,38}$ That improvement is due to a permanent physical change in the dental substrate, which was fused with the resinous monomers, creating a new tissue composed of crystallized hydroxyapatite in the presence of monomers, improving the mechanical and chemical binding of the substrate to adhesives. ${ }^{21,39}$ Based on those studies, it was assumed that a new substrate could increase the retention of the adhesive and its protective effect on erosion and abrasion. However, in our study, there was no positive effect of laser application over the adhesives tested. The wear and retention were not significantly different of the control group.

For Futurabond $U$ and G-aenial bond, a trend of increased wear when associated with the laser was observed, indicating that, somehow, the adhesive retention on the enamel surface was affected. Taking into account the limited etching effect of self-etching adhesives, smaller than that observed with phosphoric acid, the demineralized layer produced by acid monomers, responsible for retention, would have been destroyed by the melting promoted by the laser, harming adhesion. However, for Single Bond Universal, as it presented not positive effects alone, the slightly lower values of wear when associated with laser may have been due to the protective action of the laser alone and not the adhesive.

In relation to the layer thickness, the use of laser reduced the layer thickness mean from 15.27 to $13.96 \mu \mathrm{m}$ for G-aenial bond and from 7.49 to $4.24 \mu \mathrm{m}$ for Single Bond Universal, although for Futurabond $U$, the layer thickness increased from 5.06 to $9.03 \mu \mathrm{m}$. However, those differences were not statistically significant. Perhaps, the heating resulted in vaporization of the adhesive, reducing the amount remaining over the surface, diminishing the protective effect. According to our results, it can be suggested that the application of the laser after the adhesive system is unfavorable for the protective effect expected when using the adhesive.

In relation to the microhardness, the use of laser increased the mean of microhardness from 6.99 to 10.67 KHN for Futurabond and from 5.00 to $15.48 \mathrm{KHN}$ for Single Bond Universal, although for G-aenial bond, the microhardness reduced from 9.27 to $6.22 \mathrm{KHN}$. This difference can be related to the interaction between laser and adhesive components, such as filler particles or monomers. Maybe a higher amount of filler on G-aenial, responsible for the thicker layer observed without laser, had increased the absorption of light and resulted in excessive heating of the adhesive, producing damages to the monomer chains or photoinitiators. However, the higher microhardness of Single Bond and laser association was not effective in reducing the wear, since the retention was impaired.

Considering our results, it must be noted that this is an in vitro study, which has limitations in reproducing the oral conditions. Therefore, the extrapolation of the results to the clinical reality must be judicious. However, further studies are necessary, especially with regard to the type of adhesive used and the number of layers applied. Future studies can be directed to clinically evaluate the use of adhesive systems in different tooth surfaces, related with extrinsic and intrinsic acids, associated with friction of soft tissues.

\section{CONCLUSION}

Based on the obtained data, it can be concluded that the treatment of the enamel surface with Futurabond $U$ and G-aenial bond adhesive systems, as well as the Nd:YAG laser alone, was effective in reducing the enamel wear. The use of laser after the adhesive systems did not improve their efficacy.

\section{CLINICAL SIGNIFICANCE}

Erosive/abrasive wear is a prevalent condition in clinical practice affecting many patients. The association of adhesive systems and Nd:YAG laser is of considerable clinical interest because it assesses new treatments to reduce the erosive/abrasive wear that would help dentists in clinical treatment decisions to reduce enamel wear and achieve a successful treatment.

\section{REFERENCES}

1. Huysmans MC, Chew HP, Ellwood RP. Clinical studies of dental erosion and erosive wear. Caries Res 2011 May;45 (Suppl 1):60-68.

2. Davis WB, Winter PJ. The effect of abrasion on enamel and dentine and exposure to dietary acid. Br Dent J 1980 Jun;148(11-12):253-256.

3. Wiegand A, Attin T. Design of erosion/abrasion studiesinsights and rational concepts. Caries Res 2011 May;45 (Suppl1): 53-59.

4. Levy FM, Rios D, Buzalaf MA, Magalhaes AC. Efficacy of TiF and $\mathrm{NaF}$ varnish and solution: a randomized in situ study on enamel erosive-abrasive wear. Clin Oral Investig 2014 May;18(4):1097-1102.

5. Ranjitkar S, Rodriguez JM, Kaidonis JA, Richards LC, Townsend GC, Bartlett DW. The effect of casein phosphopeptide-amorphous calcium phosphate on erosive enamel and dentine wear by toothbrush abrasion. J Dent 2009 Apr;37(4):250-254.

6. Barbour ME, Shellis RP, Parker DM, Allen GC, Addy M. Inhibition of hydroxyapatite dissolution by whole casein: the effects of $\mathrm{pH}$, protein concentration, calcium, and ionic strength. Eur J Oral Sci 2008 Oct;116(5):473-478.

7. Scaramucci T, Hara AT, Zero DT, Ferreira SS, Aoki IV, Sobral MA. In vitro evaluation of the erosive potential of orange juice modified by food additives in enamel and dentine. J Dent Dec;39(12):841-848.

8. Rios D, Magalhães AC, Machado MA, da Silva SM, Lizarelli Rde F, Bagnato VS, Buzalaf MA. In vitro evaluation of enamel erosion after Nd:YAG laser irradiation and fluoride application. Photomed Laser Surg 2009 Oct;27(5):743-747. 
9. Steiner-Oliveira C, Nobre-dos-Santos M, Zero DT, Eckert G, Hara AT. Effect of a pulsed $\mathrm{CO}_{2}$ laser and fluoride on the prevention of enamel and dentine erosion. Arch Oral Biol 2010 Feb;55(2):127-133.

10. Bevilacqua FM, Zezell DM, Magnani R, da Ana PA, Eduardo Cde P. Fluoride uptake and acid resistance of enamel irradiated with Er:YAG laser. Lasers Med Sci 2008 Apr;23(2): 141-147.

11. Kwon YH, Kwon OW, Kim HI, Kim KH. Nd:YAG laser ablation and acid resistance of enamel. Dent Mater J 2003 Sep;22(3):404-411.

12. Kimura $Y$, Wilder-Smith $\mathrm{P}$, Arrastia-Jitosho AM, Liaw LH, Matsumoto K, Berns MW. Effects of nanosecond pulsed Nd: YAG laser irradiation on dentin resistance to artificial carieslike lesions. Lasers Surg Med 1997;20(1):15-21.

13. Tagomori S, Iwase T. Ultrastructural change of enamel exposed to a normal pulsed Nd-YAG laser. Caries Res 1995 Apr;29(6):513-520.

14. Kwon YH, Lee JS, Choi YH, Lee JM, Song KB. Change of enamel after Er:YAG and $\mathrm{CO}_{2}$ laser irradiation and fluoride treatment. Photomed Laser Surg 2005 Aug;23(4):389-394.

15. Sundaram G, Wilson R, Watson TF, Bartlett D. Clinical measurement of palatal tooth wear following coating by a resin sealing system. Oper Dent 2007 Nov-Dec;32(6):539-543.

16. Azzopardi A, Bartlett DW, Watson TF, Sherriff M. The measurement and prevention of erosion and abrasion. J Dent 2001 Aug;29(6):395-400.

17. Azzopardi A, Bartlett DW, Watson TF, Sherriff M. The surface effects of erosion and abrasion on dentine with and without a protective layer. Br Dent J 2004 Mar 27;196(6):351-354, discussion 339.

18. Schmidlin PR, Sener B, Attin T, Wiegand A. Protection of sound enamel and artificial enamel lesions against demineralisation: caries infiltrant versus adhesive. J Dent Oct;40(10): 851-856.

19. Franke M, Taylor AW, Lago A, Fredel MC. Influence of $\mathrm{Nd}$ :YAG laser irradiation on an adhesive restorative procedure. Oper Dent 2006 Sep-Oct;31(5):604-609.

20. Matos AB, Oliveira DC, Navarro RS, de Eduardo $C P$, Matson E. Nd:YAG laser influence on tensile bond strength of self-etching adhesive systems. J Clin Laser Med Surg 2000 Oct;18(5):253-257.

21. Goncalves SE, de Araujo MA, Damiao AJ. Dentin bond strength: influence of laser irradiation, acid etching, and hypermineralization. J Clin Laser Med Surg 1999 Apr;17(2):77-85.

22. Attin T, Wegehaupt F, Gries D, Wiegand A. The potential of deciduous and permanent bovine enamel as substitute for deciduous and permanent human enamel: Erosion-abrasion experiments. J Dent 2007 Oct;35(10):773-777.

23. Wegehaupt FJ, Taubock TT, Sener B, Attin T. Long-term protective effect of surface sealants against erosive wear by intrinsic and extrinsic acids. J Dent May;40(5):416-422.

24. Sobral MA, Lachowski KM, de Rossi W, Braga SR, Ramalho KM. Effect of Nd:YAG laser and acidulated phosphate fluoride on bovine and human enamel submitted to erosion/abrasion or erosion only: an in vitro preliminary study. Photomed Laser Surg 2009 Oct;27(5):709-713.

25. White JM, Fagan MC, Goodis HE. Intrapulpal temperatures during pulsed Nd:YAG laser treatment of dentin, in vitro. J Periodontol 1994 Mar;65(3):255-259.

26. Gutiérrez MF, Malaquias P, Hass V, Matos TP, Lourenço L, Reis A, Loguercio AD, Farago PV. The role of copper nanoparticles in an etch-and-rinse adhesive on antimicrobial activity, mechanical properties and the durability of resin-dentine interfaces. J Dent 2017 Jun;61:12-20.

27. Engle K, Hara AT, Matis B, Eckert GJ, Zero DT. Erosion and abrasion of enamel and dentin associated with at-home bleaching: an in vitro study. J Am Dent Assoc 2010 May;141(5):546-551.

28. Gohring TN, Zehnder M, Sener B, Schmidlin PR. In vitro microleakage of adhesive-sealed dentin with lactic acid and saliva exposure: a radio-isotope analysis. J Dent 2004 Mar;32(3):235-240.

29. Wiegand A, Kuhn M, Sener B, Roos M, Attin T. Abrasion of eroded dentin caused by toothpaste slurries of different abrasivity and toothbrushes of different filament diameter. J Dent 2009 Jun;37(6):480-484.

30. Magalhães AC, Romanelli AC, Rios D, Comar LP, Navarro RS, Grizzo LT, Buzalaf MA. Effect of a single application of TiF4 and $\mathrm{NaF}$ varnishes and solutions combined with Nd:YAG laser irradiation on enamel erosion in vitro. Photomed Laser Surg 2011 Aug;29(8):537-544.

31. Magalhães AC, Rios D, Machado MA, Da Silva SM, Lizarelli Rde F, Bagnato VS, Buzalaf MA. Effect of Nd:YAG irradiation and fluoride application on dentine resistance to erosion in vitro. Photomed Laser Surg 2008 Dec;26(6):559-563.

32. Zach L, Cohen G. Pulp response to externally applied heat. Oral Surg Oral Med Oral Pathol 1965 Apr;19:515-530.

33. Hermsen RJ, Vrijhoef MM. Loss of enamel due to etching with phosphoric or maleic acid. Dent Mater 1993 Sep;9(5): 332-336.

34. Perdigao J, Lopes L, Lambrechts P, Leitao J, Van Meerbeek B, Vanherle G. Effects of a self-etching primer on enamel shear bond strengths and SEM morphology. Am J Dent 1997 Jun;10(3):141-146.

35. Poggio C, Scribante A, Della Zoppa F, Colombo M, Beltrami R, Chiesa M. Shear bond strength of one-step self-etch adhesives to enamel: effect of acid pretreatment. Dent Traumatol 2013 Jan;30(1):43-48.

36. Munoz MA, Luque I, Hass V, Reis A, Loguercio AD, Bombarda NH. Immediate bonding properties of universal adhesives to dentine. J Dent 2013 May;41(5):404-411.

37. Tajima K, Nikaido T, Inoue G, Ikeda M, Tagami J. Effects of coating root dentin surfaces with adhesive materials. Dent Mater J 2009 Sep;28(5):578-586.

38. Matos AB, Oliveira DC, Kuramoto M, Jr., Eduardo $C P$, Matson E. Nd:YAG laser influence on sound dentin bond strength. J Clin Laser Med Surg 1999;17(4):165-169.

39. Cooper LF, Myers ML, Nelson DG, Mowery AS. Shear strength of composite bonded to laser-pretreated dentin. J Prosthet Dent 1988 Jul;60(1):45-49. 